Document downloaded from:

http://hdl.handle.net/10251/102607

This paper must be cited as:

Eslava-Zomeño, C.; Quiles Chuliá, MD.; Hernando Hernando, MI. (2016). Designing a Clean Label Sponge Cake with Reduced Fat Content. Journal of Food Science. 81(10):2352-2359. doi:10.1111/1750-3841.13446

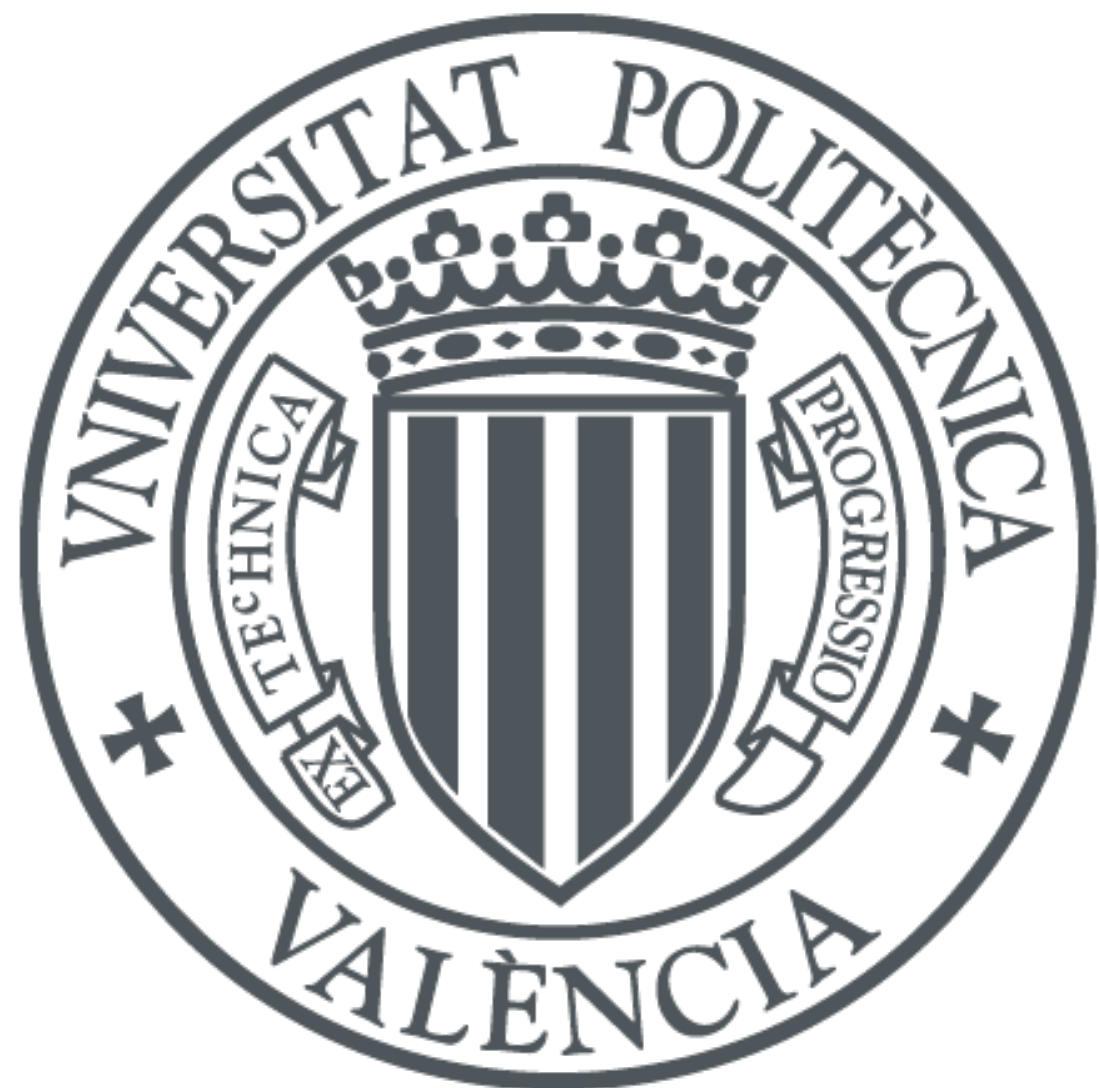

The final publication is available at

https://doi.org/10.1111/1750-3841.13446

Copyright Blackwell Publishing

Additional Information 


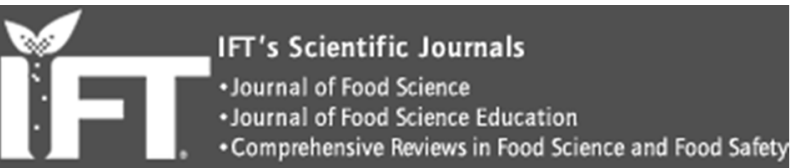

\section{Designing a Clean Label Sponge Cake with Reduced Fat Content.}

\begin{tabular}{|r|l|}
\hline Journal: & Journal of Food Science \\
\hline Manuscript ID & JFDS-2016-0206.R1 \\
\hline Manuscript Type: & 4 JFS: Food Chemistry \\
\hline Date Submitted by the Author: & n/a \\
\hline Complete List of Authors: & $\begin{array}{l}\text { Eslava-Zomeño, Cristina; Universitat Politecnica de Valencia, Food } \\
\text { Microstructure and Chemistry research group, Department of Food } \\
\text { Technology } \\
\text { Quiles, Amparo } \\
\text { Hernando, Isabel }\end{array}$ \\
\hline Keywords: & cake, flaxseed, fat replacer, structure, clean-label \\
\hline & \\
\hline
\end{tabular}

SCHOLARONE ${ }^{\text {I' }}$

Manuscripts 
Dr. Youling Xiong

Journal of Food Science

Dear Editor,

Please find enclosed a copy of the manuscript entitled "Designing a clean label sponge cake with reduced fat content" which we would like to be considered for publication in the Journal of Food Science.

In this study a natural functional ingredient derived from flaxseed, OptiSol $^{\text {TM }} 5300$, is used as fat replacer. This ingredient is high in fiber and has hydrocolloid functionality. In this research, functional cakes with reduced fat content and good acceptability by consumers are obtained avoiding E-numbers on their labels.

We hope that the paper will be suitable for publication.

Thank you in advance,

Yours sincerely

\section{Cristina Eslava Zomeño, CORRESPONDING AUTHOR}

e-mail: crieszo@upvnet.upv.es

Grupo de Microestructura y Química de Alimentos, Departamento de Tecnología de Alimentos, Universidad Politécnica de Valencia.

Camino de Vera s/n, 46022 VALENCIA (SPAIN)

Tel: +34963878230 
1 Designing a Clean Label Sponge Cake with Reduced Fat Content.

2 Cristina Eslava-Zomeño ${ }^{a^{*}}$, Amparo Quiles $^{a}$, Isabel Hernando $^{a}$

3

$4 \quad{ }^{a}$ Food Microstructure and Chemistry research group, Department of Food

5 Technology, Universitat Politècnica de València, Camino de Vera, s/n, 46022,

6 Valencia, Spain

7

8 "Corresponding author: Cristina Eslava- Zomeño, Tel.: +34 963878230,

9 E-mail address: crieszo@upvnet.upv.es

105,060 words

11 Low fat cake with functional ingredient...

12 Food Chemistry

13

14 


\section{ABSTRACT}

The fat in a sponge cake formulation was partially replaced $(0,30,50,70 \%)$ with

17 OptiSol ${ }^{\mathrm{TM}} 5300$. This natural functional ingredient derived from flax seeds, rich in fiber

18 and alpha-linoleic acid, provides a natural substitute for guar and xanthan gums,

19 avoiding E-numbers on labels. The structure and some physicochemical properties

20 of the formulations were examined, sensory analysis was conducted and changes in

21 starch digestibility due to adding this ingredient were determined. Increasing

22 quantities of OptiSol ${ }^{\mathrm{TM}} 5300$ gave harder cakes, with less weight loss during baking,

23 without affecting the final cake height. There were no significant differences ( $p>$

240.05 ) in texture, flavor and overall acceptance between the control and the $30 \%$

25 substitution cake, nor in the rapidly digestible starch values. Consequently, replacing

26 up to $30 \%$ of the fat with OptiSol ${ }^{\mathrm{TM}} 5300$ gives a new product with health benefits

27 and a clean label that resembles the full-fat sponge cake.

29 Keywords: cake; flaxseed; fat replacer; structure; clean-label.

31 Practical Application: Sponge cakes with a functional flaxseed ingredient as fat replacer were obtained in this work. This ingredient, like oil, is distributed uniformly through the batter matrix. Cakes with $30 \%$ fat replacement were very well accepted by consumers and could be prepared and sold by food industry as clean-label reduced-fat cakes. 


\section{INTRODUCTION}

Bakery products are very high consumption foods throughout the world. Sponge cakes are particularly popular and consumers consider them delicious products with certain particular organoleptic characteristics (Matsakidou and others 2010). Cakes contain approximately $15-25 \%$ fat (Matsakidou and others 2010). Fat influences the sensory and texture characteristics of the food product and, consequently, its acceptability to consumers. In sponge cakes, fat not only provides flavor but also makes it easier to incorporate air into the batter, contributing to its increase in volume, and interferes with the continuity of the gluten structure, favoring the below the recommended levels (Zahn and others 2010). Fat is the food constituent with the highest energy value (Zahn and others 2010). Excessive fat consumption is associated with obesity, cardiovascular problems and different types of cancer

52 (Román and others 2015). A promising way for the food industry to supply healthier 53 foods could therefore be to replace fat with dietary fiber in food formulations (Zahn 54 and others 2010). Various studies have been published on reducing the fat content

55 of cakes and muffins by adding different carbohydrates and fibers, such as inulin

56 (Zahn and others 2010; Rodríguez-García and others 2012; Psimouli and

57 Oreopoulou 2013; Rodríguez-García and others 2014b), $\beta$-glucan (Lee and others

58 2005; Kalinga and Mishra 2009), oat bran and flaxseed flour (Lee and others 2004),

59 cocoa fiber (Martínez-Cervera and others 2011), polydextrose (Kocer and others

60 2007), maltodextrin (Lakshminarayan and others 2006; Psimouli and Oreopoulou

612013 ) and citrus pectin (Psimouli and Oreopoulou 2013). Few references to fat

62 replacement by gums appear to have been published. Zambrano and others (2004) 
used guar and xanthan gums to obtain low-fat sponge cakes, Khouryieh and others

64 (2005) prepared muffins in which they replaced fat with a mixture of maltodextrin and xanthan gum and Kaur and others (2000) used guar gum and carboxymethyl cellulose to reduce the fat content of muffins.

The importance of gums lies in their ability to control the rheological characteristics of an aqueous system. They can also influence the stabilization of emulsions and help to suspend particles, control crystallization and inhibit syneresis (Zambrano and others 2004).

In the present study, a functional ingredient with hydrocolloid capacity derived from flax seeds was used as a fat substitute. This ingredient can be used to replace guar and xanthan gums and, being a natural product, allows clean labeling of the food, avoiding E-numbers.

Flax seeds are a potential source for functional food formulations (Marpalle and others 2014). They are rich in health beneficial nutrients (Shearer and Davies 2005) and present a unique nutritional profile with a high concentration of polyunsaturated fatty acids ( $73 \%$ of the total fatty acids), a moderate concentration of monounsaturated fatty acids (18\%) and a low concentration of saturated fatty acids (9\%). Linoleic acid comprises $16 \%$ and alpha-linolenic acid (ALA) $57 \%$ of their total fatty acids (Marpalle and others 2014). ALA is an omega-3 fatty acid which is involved in reducing inflammatory processes and plays an important role in reducing/preventing cardiovascular diseases, osteoporosis, diabetes and digestive system diseases (Mercier and others 2014). Flax seeds contain approximately $28 \%$ fiber, of which a third is soluble. Soluble fiber is associated with the ability to reduce cholesterol and regulate blood sugar levels. The rest of the dietary fiber is insoluble. Insoluble fiber favors increased stool bulk and reduces bowel transit time, so it helps to prevent constipation and may provide protection against colon cancer (Moraes and others 2010). 
The aim of this study was to assess the effect on the structure and the physicochemical and sensory properties of sponge cakes of using a natural functional ingredient derived from flaxseed to replace part of the fat in their formulation. A further aim was to study changes in starch digestibility as a result of adding this ingredient to the sponge cake formulation.

\section{MATERIALS AND METHODS}

\subsection{Ingredients}

The ingredients used in the preparation of the cake batters were: wheat flour (Harinas Segura S.L, Torrente, Spain, composition provided by the supplier: 13.50$15.50 \mathrm{~g} / 100 \mathrm{~g}$ moisture, 9-11 g/100 g proteins); sugar (AB Azucarera Iberica S.L.U., Madrid, Spain); liquid pasteurized egg white and yolk (Ovocity, Llombay, Spain); skim milk (Corporación Alimentaria Peñasanta, S.A., Siero, Spain); refined sunflower oil (Aceites del Sur-Coosur, S.A., Vilches, Spain); OptiSol ${ }^{\mathrm{TM}} 5300$ (natural ingredient derived from flaxseed; Glambia Nutritionals Ltd, Kilkenny, Ireland; specifications provided by the supplier: $28-36 \mathrm{~g} / 100 \mathrm{~g}$ protein, 8-12 g/100 $\mathrm{g}$ moisture, $15-20 \mathrm{~g} / 100 \mathrm{~g}$ fat, 30-40 g/100 g carbohydrate, 25-37 g/100 g dietary fiber) sodium bicarbonate and citric acid (Sodas y Gaseosas A. Martínez, S.L., Cheste, Spain); salt and distilled water. Oil was used instead of shortening as usually done in Mediterranean countries (Rodriguez-Garcia and others, 2012; Martinez-Cervera and others 2011)

\subsection{Batter and cake preparation}

Four formulations were prepared: the control formulation (R0) and three formulations (R30, R50 and $\mathrm{R} 70$ ) where fat was replaced at $30 \%, 50 \%$ and $70 \%$ respectively, by increasing amounts of OptiSol ${ }^{\mathrm{TM}} 5300$ (Table 1). The fat content of OptiSol ${ }^{\mathrm{TM}} 5300$ was taken into account to calculate the level of fat replacement in the 
117 different formulations. In order to achieve the proper dispersion for OptiSol ${ }^{\mathrm{TM}} 5300$ to

118 act as a fat mimetic, the appropriate amounts of water were added for an

119 OptiSol ${ }^{\mathrm{TM}}$ 5300-to-water ratio of 1:5.

120 The batters were prepared according to the all-in mixing procedure proposed by

121 Rodríguez-García and others (2014a), with some modifications. The liquid eggs,

122 milk and water were placed in a Kenwood Major Classic mixer (Havant, England,

123 UK). The dry ingredients (wheat flour, sugar, OptiSol ${ }^{\mathrm{TM}} 5300$, sodium bicarbonate

124 and citric acid and salt) were added to the liquids, and the oil was finally placed on

125 the top. The mixing proceeded using a wire whisk at speed 1 for $30 \mathrm{sec}$, followed by

$1261 \mathrm{~min}$ at speed 2 and $3 \mathrm{~min}$ at speed 3.

127 For cake preparation, a conventional oven (Electrolux, EOC3430DOX,

128 Stockholm, Sweden) was preheated to $180^{\circ} \mathrm{C}$ for $30 \mathrm{~min}$, and the batters $(700 \mathrm{~g})$

129 were placed in a Pyrex baking pan (diameter $=20 \mathrm{~cm}$ ) and baked at $180^{\circ} \mathrm{C}$ for 43

$130 \mathrm{~min}$. The cakes were then kept at room temperature for at least $1 \mathrm{~h} 30 \mathrm{~min}$ before

131 being analyzed. All the batters and cakes were prepared in triplicate and the

132 analyses were performed within 24 hours of their preparation.

\subsection{Confocal laser scanning microscopy (CLSM)}

Equipment and dyes. A Nikon confocal microscope C1 unit fitted on a Nikon

136 Eclipse E800 microscope (Nikon, Tokyo, Japan) was used. An Ar laser line (488nm)

137 was employed as the light source to excite the fluorescent dyes: Rhodamine B and

138 Nile Red. Rhodamine B (Fluka, Sigma-Aldrich, St. Louis, Mo., U.S.A), with $\lambda_{\text {ex } \max } 488$

$139 \mathrm{~nm}$ and $\lambda_{\mathrm{em} \max } 580 \mathrm{~nm}$, was solubilized in distilled water at $0.2 \mathrm{~g} / 100 \mathrm{~mL}$. This dye

140 was used to stain proteins and carbohydrates. Nile Red (Fluka, Sigma-Aldrich), with

$141 \lambda_{\text {ex max }} 488 \mathrm{~nm}$ and $\lambda_{\text {em max }} 515 \mathrm{~nm}$, was solubilized in PEG 200 at $0.1 \mathrm{~g} / \mathrm{L}$ and used to

142 stain fat. The objective lenses were 40x/1.0 and 60x/1.40 NA/Oil/ Plan Apo VC

143 Nikon. 
144 Sample viewing. A microscopy slide was prepared with 2 razor blades stuck to

145 the glass (Alava and others 1999; Sahi and Alava 2003). A drop of batter was

146 placed on the slide, in the central gap between the blades. Rhodamine B solution

147 and Nile Red solution were added and the cover slide was carefully positioned to

148 exclude air pockets. The images were observed and stored with a $1024 \times 1024$ pixel

149 resolution using the microscope software (EZ-C1 v.3.40, Nikon).

150

151

\subsection{Weight loss during baking}

153 water content of each formulation (Rodríguez-García and others 2014b). The weight

154 loss during baking was calculated as follows:

155

156

$W L(g / 100 \mathrm{~g})=[(B-C / I W) \times 100]$

157

where:

$159 \quad \mathrm{WL}=$ weight loss during baking

$160 \mathrm{~B}=$ weight (in grams) of batter before baking.

$161 \mathrm{C}=$ weight (in grams) of cake after baking

162 IW = initial water content (in grams). triplicate.

\subsection{Cake height}

The maximum cake height was measured on the vertical cross section of the 170 product, using ImageJ software (National Institutes of Health, Bethesda, MD, USA). 
171 The baked product was cut and photographed with a digital camera (E-510

172 Olympus, Hamburg, Germany). The images were stored in a $3648 \times 2736$ pixel

173 format. The measurements were performed in triplicate.

\subsection{Macroscopic structure of the crumb}

176 The cakes were cut vertically in the central area and scanned using a HP

177 Scanjet G2710 scanner (Hewlett-Packard, Palo Alto, CA, USA). The scanned

178 images were analyzed using ImageJ software (National Institutes of Health,

179 Bethseda, MD, USA). The image was cropped to a $5 \times 5 \mathrm{~cm}$ section, on which the

180 analysis was performed. Firstly, the image was split into color channels, then the

181 contrast was enhanced and finally the image was binarized after applying a

182 grayscale threshold. For each formulation, three different images were analyzed.

\subsection{Color measurements}

The instrumental measurements of the cake crust and crumb color were made with a Chroma meter CR-400 (Konica Minolta Sensing Americas, Inc., Ramsey, NJ, USA). The results were expressed in accordance with the CIELAB system, with reference to illuminant $\mathrm{C}$ and a visual angle of $2{ }^{\circ}$. The parameters determined were $L^{*}\left(L^{*}=0\right.$ [black], $L^{*}=100$ [white] $), a^{*}\left(-a^{*}=\right.$ greenness, $+a^{*}=$ redness $), b^{*}\left(-b^{*}=\right.$ blueness, $+b^{*}=$ yellowness $), C^{*}{ }_{\mathrm{ab}}\left(\right.$ chroma $\left.\left[C^{*}{ }_{\mathrm{ab}}=\left(a^{* 2}+b^{\star 2}\right)^{1 / 2}\right]\right)$ and $h_{\mathrm{ab}}$ (hue $\left[h_{\mathrm{ab}}=\right.$ $\left.\left.\arctan \left(b^{*} / a^{*}\right)\right]\right)$.

192 The total color difference $\left(\Delta E^{*}\right)$ was calculated as follows (Francis and 193 Clydesdale 1975):

$$
\Delta E^{*}=\left[\left(\Delta L^{*}\right)^{2}+\left(\Delta a^{*}\right)^{2}+\left(\Delta b^{*}\right)^{2}\right]^{1 / 2}
$$


The values used to determine whether the total color difference was appreciable by the human eye were (Baixauli and others 2008):

199

\subsection{Sensory analysis}

140 consumers (aged 18 to 64 ) were recruited among employees and students of the Universitat Politècnica de València. The samples were assessed in a standardized tasting room equipped with individual booths. Each consumer received 4 pieces of cake ( 1 piece each of the control with no OptiSol ${ }^{\mathrm{TM}} 5300$ and the 3 fatreplacement cakes). 3-digit random numbers were used to code the pieces of cakes. They were served at room temperature in random order. Water was supplied to clean the consumers' mouths between each sample. Consumer acceptance testing was performed with a successive category scale to score the "appearance", "texture", "taste", and "overall acceptance" of the product. The scale was a 5-point 
224 hedonic scale labeled 5 = like very much, 4 = like moderately, 3 = neither like nor 225 dislike, 2 = dislike moderately and $1=$ dislike very much.

\subsection{Field Emission Scanning Electron Microscopy (FESEM)}

Samples of each formulation $\left(0.5 \mathrm{~cm}\right.$ each side) were frozen at $-80^{\circ} \mathrm{C}$ and lyophilized (Telstar, Lyoquest 55, Terrassa, Spain). The samples were coated with platinum in a vacuum, then observed in a field emission scanning electron microscope (FESEM) (Zeiss, Ultra 55, Oberkochen, Germany).

\subsection{In vitro digestion} capacity) maintained at $37^{\circ} \mathrm{C}$ with continuous magnetic stirring at $120 \mathrm{rpm}$ in a temperature-controlled circulating water bath throughout the test.

The in vitro digestions were carried out according to the method of Sozer and others

238 (2014), with modifications. $4 \mathrm{~g}$ of ground sample, $100 \mathrm{~mL} 0.05 \mathrm{~mol} / \mathrm{L}$ of sodium potassium phosphate buffer ( $\mathrm{pH}$ 6.9) and $5 \mathrm{~mL}$ of $2.5 \mathrm{~g} / 100 \mathrm{~mL}$ pancreatin (P3292, pancreatin from porcine pancreas containing trypsin, amylase, lipase, ribonuclease and protease, Sigma-Aldrich, St. Louis, Mo., U.S.A) in $0.1 \mathrm{~mol} / \mathrm{L}$ of $\mathrm{pH} 6$ maleate buffer were placed in the jacketed glass reactor and maintained there for $120 \mathrm{~min}$. Aliquots $(7.5 \mathrm{~mL})$ were removed at $20,60,90$ and $120 \mathrm{~min}$, placed in boiling water for $5 \mathrm{~min}$, and cooled on ice. They were then centrifuged at $6600 \mathrm{rpm}$ for $5 \mathrm{~min}$ and the supernatant was analyzed for reducing sugar content using the dinitrosalicylic acid (DNS) colorimetric method. The amount of digested starch was determined by multiplying the reducing sugar values by a 0.9 stoichiometric conversion constant for glucose to starch (Hardacre and others 2015). For each formulation, two different sponge cakes were analyzed. 


\subsection{Statistical analysis}

Analysis of variance (ANOVA) was performed on the data using the Statgraphics

Centurion XVI.I software package (StatPoint Technologies, Inc., Warrenton, VA,

255 USA). Fisher's least significant difference (LSD) test was used to evaluate mean

256 difference values $(p<0.05)$.

\section{RESULTS AND DISCUSSION}

\subsection{Confocal laser scanning microscopy (CLSM) of the batters}

Figure 1 shows CLSM images of the sponge cake batters prepared with different levels of fat substitution (R0, R30, R50 and R70).

In the control batter (R0), a continuous phase with a homogeneous appearance can be seen, stained red with rhodamine. It is mainly formed by interaction between the proteins of the sponge cake ingredients: milk, egg and gluten. Associated with this protein network, intact starch granules in black and fat globules stained green with Nile Red can also be identified. The fat globules are of different sizes, and many are clustered together, but hardly any coalescence can be seen. interaction between the proteins of the different ingredients in the formulation (milk, egg, gluten and OptiSol ${ }^{\mathrm{TM}} 5300$ ), and probably also the fat phase of the functional ingredient (OptiSol ${ }^{\mathrm{TM}} 5300$ ). Unlike the sunflower oil, this fat phase does not appear

272 in the form of globules but interacts with the protein fraction of the formulation.

273 Another extensive dark or blackish network can be observed superimposed on the

274 continuous phase. It is probably composed of the carbohydrate components of the

275 OptiSol ${ }^{\mathrm{TM}} 5300$ ingredient added to the formulation. The starch granules and fat

276 globules can be seen associated with this network. Coalescence between the 277 globules is slightly higher than in the control batter. 
At the highest substitution level (R70), the extent, compaction and intensity of

\section{9}

280 the dark/blackish network associated with the addition of OptiSol ${ }^{\mathrm{TM}} 5300$ have increased. Also, as the levels of fat replacement in the sponge batter rise, fewer fat globules can be seen. Coalescence between the globules appears not to be significant in the high-substitution batters. The decreased fat content of these formulations appears to minimize coalescence.

\subsection{Weight loss during baking and cake height}

In general, adding OptiSol ${ }^{\mathrm{TM}} 5300$ to the formulation led to significant low weight loss during baking $(p<0.05)$ from $21.48 \pm 0.51 \mathrm{~g} / 100 \mathrm{~g}$ in the control $(R 0)$ to $20.09 \pm 0.36 \mathrm{~g} / 100 \mathrm{~g}$ in R70 (Table 2). Hydrocolloids have the ability to increase moisture retention, although this depends on their chemical structure and interaction with the other ingredients (Gomez and others 2007), and consequently to reduce weight loss in the food. From this point of view, OptiSol TM 5300 presented hydrocolloid behavior in the sponge cake. The present results agree with those obtained by Khouryieh and others (2005), who observed lower moisture loss in muffins prepared with xanthan gum and maltodextrin as fat replacers than in those prepared with fat or with maltodextrin alone.

The addition of OptiSol ${ }^{\mathrm{TM}} 5300$ to the formulation did not influence the maximum height of the sponge cakes. No significant differences $(p>0.05)$ between formulations were found in the values for this parameter (Table 2).

\subsection{Macroscopic structure of the crumb}

Figure 2 shows scanned, contrasted and binarized images of the different sponge cakes (R0, R30, R50 and R70).

The crumb macrostructure of the control cake (R0) was practically homogenous (Figure 2). In contrast, a series of diffusion pathways were observed in the crumb of 
the sponge cakes formulated with OptiSol ${ }^{\mathrm{TM}} 5300$. Furthermore, these pathways appeared to a greater extent in the formulations with higher levels of substitution ( $R 50$ and $\mathrm{R} 70$ ) than in the R30 sponge cake.

\subsection{Color measurement} sponge cakes studied are shown in Table 3.

In the crust, the values for parameters $L^{*}, a^{*}, b^{*}$ and $C^{*}{ }_{a b}$ were significantly lower $(p<0.05)$ in the control formulation $(R 0)$ than in the fat substitution formulations studied (R30, R50 and R70), and no significant differences $(p>0.05)$ were observed between the formulations with the different levels of substitution. Lee and others (2004) also found significant differences in $L^{*}$ for the crust of cakes in which fat had been replaced by oat bran and powdered flaxseed: the greater the replacement of fat by these ingredients, the higher the $L^{*}$ values obtained, indicating greater luminosity. As regards hue $\left(h_{a b}{ }^{*}\right)$, significant differences $(p<0.05)$ were found between the control cake and the formulations with higher levels of substitution. Lastly, differences in overall color $\left(\Delta E^{*}>3\right)$, visible to the human eye, were found between the control cake and the other formulations. The reason for these differences was that the surface color became less dark as more OptiSol ${ }^{\mathrm{TM}} 5300$ was included in the formulation. Shearer and Davies (2005) also

325 found overall color differences in muffins prepared with $5 \mathrm{~g}$ flaxseed flour/100 $\mathrm{g}$ batter, but not in those prepared with $2 \mathrm{~g}$ of this flour $100 \mathrm{~g}$ batter.

No significant differences in the crumb of the four types of sponge cake studied were found for $L^{*}, b^{*}$ or $C^{*}{ }_{a b}$ (Table 3$)$. However, the $a^{*}$ value rose significantly $(p<$ 0.05 ) as greater quantities of OptiSol ${ }^{\mathrm{TM}} 5300$ were added to the formulation. Lee and others (2004) also encountered higher $a^{*}$ values on increasing the level of flaxseed powder used to replace fat in cakes. In contrast, the $\mathrm{h}^{*}{ }_{a b}$ value fell significantly as 
332 more OptiSol ${ }^{\mathrm{TM}} 5300$ was added, as shown in Table 3. Lastly, no significant

333 differences in overall color were encountered, as all the $\Delta \mathrm{E}^{*}$ values were below 3 .

\subsection{Sponge cake texture}

Table 4 shows the parameters obtained from the texture profile analysis (TPA) curves. control cake and R30. However, the addition of OptiSol ${ }^{\mathrm{TM}} 5300$ in the formulations with higher fat replacement (R50 and R70) gave place to significant $(p<0.05)$ higher hardness values. Zambrano and others (2004) obtained a significantly higher firmness value in cake prepared with xanthan gum and $50 \%$ less fat than the control. Khouryieh and others (2005) also found significantly higher hardness values in muffins prepared with maltodextrin and xanthan gum to replace fat, when compared with the control.

The springiness and cohesiveness values indicate that there were no significant differences between the formulations studied. This could be because all the sponge cakes contained the same flour and, therefore, the same proportion of gluten proteins, which are responsible for the elasticity and strength of the batter.

The chewiness values followed a similar trend to those for hardness. No significant differences $(p>0.05)$ were observed between control cake and R30. In contrast significant differences were observed between $\mathrm{R} 0$ and cakes with higher quantity of OptiSol ${ }^{\mathrm{TM}} 5300$ in their formulations (R50 and R70). R70 was the chewiest sponge cake - which could be related to a more compact cake - which is why it was necessary to apply more force compared to the other cakes to ready it for swallowing. Khouryieh and others (2005) also found significantly higher chewiness values than those of the control in muffins prepared with less fat and the addition of maltodextrin and xanthan gum. 


\subsection{Sensory analysis}

The mean sensory acceptability values for the appearance, texture, taste and overall acceptance of the control cake and the sponge cakes prepared with different levels of fat replacement are shown in Figure 3.

The statistical analysis showed that there were no significant differences $(p>$ $0.05)$ between the control cake (R0) and R30 for the attributes of texture, taste and overall acceptance. In the case of taste, R0 and R50 did not exhibit any significant differences either. Nevertheless, the appearance value was significantly lower $(p<$ 0.05) for R30 than for the control.

For all the attributes studied, it was found that the sensory acceptability fell significantly as the quantity of OptiSol ${ }^{\mathrm{TM}} 5300$ in the formulation rose, since significantly lower values were obtained on comparing R50 with R0 (except for the attribute of taste, as commented above) and R70 with R0. Of all the fat replacement formulations studied, R30 seemed to have the highest sensory acceptability.

\subsection{Field emission scanning electron microscopy (FESEM)}

Figure 4 shows the images obtained through field emission scanning electron microscopy (FESEM), allowing observation of the sponge cake microstructure.

The structure of the control cake (R0) can be seen to be made up of a welldeveloped hydrated protein network, mainly formed by the gluten from the flour, into which the rest of the ingredients have been incorporated. The gluten network contains the partially gelatinized starch granules and the oil has acted as a lubricant, creating a flexible continuous structure. The fat globules coalesced during baking and liberated fat, which was incorporated into the matrix, creating a film coating, as can be seen in Figure 4.

The R30 cake shows a more irregular microstructure, as the oil coating is less extensively distributed compared to R0. With the higher fat replacement levels (R50 
and R70), it becomes more difficult it to find the oil coating in the images. It may also be seen that as greater quantities of OptiSol ${ }^{\mathrm{TM}} 5300$ were added to in the formulation, this ingredient acted as a filler in the spaces within the protein network, making the sponge cake more compact. This information was correlated with the textural values, since the hardness and chewiness increased significantly, compared with the R0 and R30 cakes, as the OptiSol ${ }^{\mathrm{TM}} 5300$ content rose.

\subsection{In vitro digestion}

Table 5 shows the proportion of starch digested in vitro for each of the sponge cakes studied.

The gelatinized starch fraction digested during the first 20 min of the digestion process is considered rapidly digestible starch (RDS) (Hardacre and others 2015). After subjecting the different cakes (R0, R30, R50 and R70) to 20 min in vitro digestion, no significant differences $(p>0.05)$ in RDS values were found between R0, R30 and R50 cakes; being RDS values in R70 significantly lower $(p<0.05)$. The digestibility of starch values significantly decreased $(p<0.05)$ in cakes with higher levels of substitution (R70) after 60, 90 and 120 min too. Adding fiber when processing foods is known to limit starch gelatinisation and mask the starch granules, increasing the proportion of resistant starch as observed by Hardacre et al., (2015). This could be also related to the field emission scanning electron microscope (FESEM) images, where the starch granules in the R70 cake matrix were observed to be very compact within the matrix, which would limit their physical accessibility to the digestive enzymes.

\section{CONCLUSIONS}

OptiSol ${ }^{\mathrm{TM}} 5300$, a functional ingredient derived from flax seeds, can be used to replace fat in sponge cakes when formulating low fat products; as a natural product, 
413 it allows clean labeling avoiding E-numbers. When preparing fat reduced cakes

414 using this ingredient it is found that sponge cakes with $30 \%$ fat replacement present

415 good sensory acceptability to consumers. The hydrocolloid properties of

416 OptiSol ${ }^{\mathrm{TM}} 5300$ avoid moisture loss without affecting batter rise, and the hardness

417 and crumb color of the cakes are similar than in control. Sponge cakes with $30 \%$ fat

418 replacement by this functional ingredient could be elaborated by food industry as an

419 appropriate strategy to reduce fat and calories in this bakery product.

420

ACKNOWLEDGMENTS

422 The authors are grateful to INIA for financial support through the BERRYPOM-

423 Adding value to fruit processing waste: innovative ways to incorporate fibers from

424 berry pomace in baked and extruded cereal-based foods project included in the

425 ERA-NET - SUSFOOD program.

426 They also wish to thank Mary Georgina Hardinge for English translation and copy

427 editing assistance, and to the Electron Microscopy Service of the Universitat

428 Politècnica de Valencia.

429

430 AUTHOR CONTRIBUTIONS

431 Cristina Eslava-Zomeño elaborated the cakes and carried out experimental work

432 on physicochemical analysis and in vitro digestion determinations. Amparo Quiles

433 collaborated in the in vitro digestion determinations and carried out the CLSM

434 studies. Isabel Hernando supervised the work and carried out the FESEM studies.

435

\section{REFERENCES}

437 Alava JM, Whitworth MB, Sahi SS, Catterall PF. 1999. Fat emulsifiers and their

438 functionality in cake batters: image analysis of the batter bubble distribution. 
In: Campbell GMWC, Panediella SS, Niranjan K, editors. Bubbles in food. St. Paul, Minn.: American Association of Cereal Chemists. p. 273-82.

Baixauli R, Salvador A, Fiszman SM. 2008. Textural and colour changes during storage and sensory shelf life of muffins containing resistant starch. Eur Food Res Technol 226(3):523-30.

Francis FJ, Clydesdale FM. 1975. Food colorimetry: theory and applications. Westport, Conn.: The Avi Publishing Co., Inc.

Gomez M, Ronda F, Caballero PA, Blanco CA, Rosell CM. 2007. Functionality of different hydrocolloids on the quality and shelf-life of yellow layer cakes. Food Hydrocolloid 21(2):167-73.

Hardacre AK, Yap S-Y, Lentle RG, Monro JA. 2015. The effect of fibre and gelatinised starch type on amylolysis and apparent viscosity during in vitro digestion at a physiological shear rate. Carbohyd Polym 123:80-8.

Kalinga D, Mishra VK. 2009. Rheological and physical properties of low fat cakes produced by addition of cereal $\beta$-glucan concentrates. J Food Process Preserv 33(3):384-400.

Kaur A, Singh G, Kaur H. 2000. Studies on use of emulsifiers and hydrocolloids as fat replacers in baked products. J Food Sci Technol 37(3):250-5.

Khouryieh HA, Aramouni FM, Herald TJ. 2005. Physical and sensory characteristics of no-sugar-added/low-fat muffin. J Food Quality 28(5-6):439-51.

Kocer D, Hicsasmaz Z, Bayindirli A, Katnas S. 2007. Bubble and pore formation of the high-ratio cake formulation with polydextrose as a sugar-and fat-replacer. J Food Eng 78(3):953-64.

Lakshminarayan SM, Rathinam V, KrishnaRau L. 2006. Effect of maltodextrin and emulsifiers on the viscosity of cake batter and on the quality of cakes. J Sci Food Agric 86(5):706-12. 
Lee S, Inglett GE, Carriere CJ. 2004. Effect of nutrim oat bran and flaxseed on rheological properties of cakes. Cereal Chem 81(5):637-42.

Lee S, Kim S, Inglett GE. 2005. Effect of shortening replacement with oatrim on the physical and rheological properties of cakes. Cereal Chem 82(2):120-4.

Marpalle P, Sonawane SK, Arya SS. 2014. Effect of flaxseed flour addition on physicochemical and sensory properties of functional bread. LWT-Food Sci Technol 58(2):614-9.

Martínez-Cervera S, Salvador A, Muguerza B, Moulay L, Fiszman SM. 2011. Cocoa fibre and its application as a fat replacer in chocolate muffins. LWT-Food Sci Technol 44(3):729-36.

Matsakidou A, Blekas G, Paraskevopoulou A. 2010. Aroma and physical characteristics of cakes prepared by replacing margarine with extra virgin olive oil. LWT-Food Sci Technol 43(6):949-57.

Mercier S, Villeneuve S, Moresoli C, Mondor M, Marcos B, Power KA. 2014. Flaxseed-Enriched Cereal-Based Products: A Review of the Impact of Processing Conditions. Compr Rev Food Sci F 13(4):400-12.

Moraes ÉA, Dantas MIdS, Morais DdC, Silva COd, Castro FAFd, Martino HSD, Ribeiro SMR. 2010. Sensory evaluation and nutritional value of cakes prepared with whole flaxseed flour. Cienc Tecnol Alime 30(4):974-9.

Psimouli V, Oreopoulou V. 2013. The Effect of Fat Replacers on Batter and Cake Properties. J Food Sci 78(10):C1495-C502.

Rodríguez-García J, Sahi SS, Hernando I. 2014a. Optimizing Mixing during the Sponge Cake Manufacturing Process. Cereal Food World 59(6):287-92.

Rodríguez-García J, Salvador A, Hernando I. 2014b. Replacing fat and sugar with inulin in cakes: Bubble size distribution, physical and sensory properties. Food Bioprocess Technol 7(4):964-74. 
491 Rodríguez-García J, Puig A, Salvador A, Hernando I. 2012. Optimization of a

492 sponge cake formulation with inulin as fat replacer: structure,

493 physicochemical, and sensory properties. J Food Sci 77(2):C189-C97.

494 Román L, Santos I, Martínez MM, Gómez M. 2015. Effect of extruded wheat flour as

495 a fat replacer on batter characteristics and cake quality. J Food Sci

$496 \quad$ Technol:1-8.

497 Sahi SS, Alava JM. 2003. Functionality of emulsifiers in sponge cake production. J

$498 \quad$ Sci Food Agric 83(14):1419-29.

499 Shearer AEH, Davies CGA. 2005. Physicochemical properties of freshly baked and

500 stored whole-wheat muffins with and without flaxseed meal. J Food Quality

$501 \quad 28(2): 137-53$

502 Sozer N, Cicerelli L, Heiniö R-L, Poutanen K. 2014. Effect of wheat bran addition on

503 in vitro starch digestibility, physico-mechanical and sensory properties of

504 biscuits. J Cereal Sci 60(1):105-13.

505 Zahn S, Pepke F, Rohm H. 2010. Effect of inulin as a fat replacer on texture and

506 sensory properties of muffins. Int J Food Sci Technol 45(12):2531-7.

507 Zambrano F, Despinoy P, Ormenese RCSC, Faria EV. 2004. The use of guar and

508 xanthan gums in the production of 'light'low fat cakes. Int J Food Sci Technol

$509 \quad 39(9): 959-66$.

510

511 
513 Table 1. Composition of the formulations studied (g/100 g, wheat flour basis)

514

\begin{tabular}{ccccc}
\hline Ingredients & R0 & R30 & R50 & R70 \\
\hline Wheat flour & 100 & 100 & 100 & 100 \\
Sugar & 100 & 100 & 100 & 100 \\
Egg yolk & 27 & 27 & 27 & 27 \\
Egg white & 54 & 54 & 54 & 54 \\
Skim milk & 50 & 50 & 50 & 50 \\
Water & 0 & 15 & 25 & 35 \\
OptiSol ${ }^{\text {TM }}$ 5300 & 0 & 3 & 5 & 7 \\
Sunflower oil & 46 & 31.6 & 22 & 12.4 \\
Sodium bicarbonate & 4 & 4 & 4 & 4 \\
Citric acid & 3 & 3 & 3 & 3 \\
Salt & 1.5 & 1.5 & 1.5 & 1.5
\end{tabular}

515 R0: control sponge cake, R30: sponge cake with $30 \mathrm{~g} / 100 \mathrm{~g}$ of fat replacement; R50:

516 sponge cake with $50 \mathrm{~g} / 100 \mathrm{~g}$ of fat replacement; R70: sponge cake with $70 \mathrm{~g} / 100 \mathrm{~g}$

517 of fat replacement.

518 
519 Table 2. Mean weight loss during baking and maximum height of the sponge cakes, 520 by formulation.

\begin{tabular}{lcccc}
\hline Parameter & R0 & R30 & R50 & R70 \\
\hline Weight loss (\%) & $21.48^{\mathrm{a}}(0.51)$ & $20.68^{\mathrm{b}}(0.27)$ & $19.78^{\mathrm{c}}(0.23)$ & $20.09^{\mathrm{bc}}(0.36)$ \\
Height (cm) & $10.06^{\mathrm{a}}(0.79)$ & $9.72^{\mathrm{a}}(0.10)$ & $9.43^{\mathrm{a}}(0.71)$ & $9.32^{\mathrm{a}}(0.41)$ \\
\hline Values in parentheses are the standard deviations. Means in the same row without a \\
common letter are significantly different $(\mathrm{p}<0.05)$ according to the LSD multiple range \\
test (n=3); R0: control sponge cake, R30: sponge cake with $30 \mathrm{~g} / 100 \mathrm{~g}$ of fat \\
replacement; R50: sponge cake with $50 \mathrm{~g} / 100 \mathrm{~g}$ of fat replacement; R70: sponge cake \\
with 70 g/100 g of fat replacement.
\end{tabular}

521 
Table 3. Mean values of sponge cake color parameters, by formulation

\begin{tabular}{|c|c|c|c|c|c|c|c|c|}
\hline \multirow[b]{2}{*}{ Parameter } & \multicolumn{4}{|c|}{ Crust color } & \multicolumn{4}{|c|}{ Crumb color } \\
\hline & Ro & R30 & R50 & R70 & Ro & R30 & R50 & R70 \\
\hline$L^{*}$ & $40.05^{a}(1.12)$ & $42.57^{b}(1.81)$ & $43.51^{\mathrm{b}}(1.90)$ & $43.06^{b}(2.22)$ & $66.86^{a}(1.45)$ & $66.39^{a}(1.99)$ & $66.47^{\mathrm{a}}(0.83)$ & $65.40^{\mathrm{a}}(2.02)$ \\
\hline$a^{*}$ & $14.91^{a}(0.5)$ & $15.35^{\mathrm{b}}(0.37)$ & $15.31^{\mathrm{b}}(0.55)$ & $15.59^{b}(0.52)$ & $-2.23^{a}(0.20)$ & $-1.11^{b}(0.24)$ & $-0.60^{c}(0.16)$ & $-0.20^{d}(0.12)$ \\
\hline $\mathbf{b}^{*}$ & $24.95^{\mathrm{a}}(2.18)$ & $27.30^{b}(2.26)$ & $28.00^{b}(2.29)$ & $28.69^{b}(1.67)$ & $22.97^{\mathrm{a}}(1.61)$ & $22.48^{\mathrm{a}}(1.46)$ & $23.06^{\mathrm{a}}(1.25)$ & $22.28^{\mathrm{a}}(0.60)$ \\
\hline$C^{*}{ }_{a b}$ & $29.08^{\mathrm{a}}(2.00)$ & $31.34^{\mathrm{b}}(1.92)$ & $31.94^{\mathrm{b}}(1.88)$ & $32.66^{\mathrm{b}}(1.42)$ & $23.08^{\mathrm{a}}(1.61)$ & $22.50^{\mathrm{a}}(1.46)$ & $23.06^{a}(1.25)$ & $22.29^{\mathrm{a}}(0.60)$ \\
\hline $\mathbf{h}^{*}{ }_{\mathrm{ab}}$ & $59.02^{\mathrm{a}}(2.01)$ & $60.54^{\mathrm{ab}}(2.26)$ & $61.20^{b}(2.59)$ & $61.42^{\mathrm{b}}(1.79)$ & $95.56^{\mathrm{a}}(0.56)$ & $92.85^{\mathrm{b}}(0.63)$ & $91.48^{\mathrm{C}}(0.38)$ & $90.52^{d}(0.30)$ \\
\hline$\Delta \mathrm{E}^{*}$ & & 3.47 & 4.62 & 4.84 & & 1.31 & 1.68 & 2.59 \\
\hline
\end{tabular}

523 Values in parentheses are the standard deviations. Means in the same row without a common letter are significantly different $(p<0.05)$ according to the

524 LSD multiple range test ( $\mathrm{n}=12)$; R0: control sponge cake, R30: sponge cake with $30 \mathrm{~g} / 100 \mathrm{~g}$ of fat replacement; R50: sponge cake with $50 \mathrm{~g} / 100 \mathrm{~g}$ of fat 
527 Table 4. Mean values of sponge cake texture properties, by formulation

\begin{tabular}{ccccc}
\hline Formulation & $\begin{array}{c}\text { Hardness } \\
(\mathbf{N})\end{array}$ & Springiness & Cohesiveness & $\begin{array}{c}\text { Chewiness } \\
(\mathbf{N})\end{array}$ \\
\hline R0 & $5.35^{\mathrm{a}}(0.71)$ & $0.88^{\mathrm{a}}(0.01)$ & $0.73^{\mathrm{a}}(0.00)$ & $3.45^{\mathrm{a}}(0.43)$ \\
R30 & $5.25^{\mathrm{a}}(0.66)$ & $0.89^{\mathrm{a}}(0.01)$ & $0.73^{\mathrm{a}}(0.01)$ & $3.42^{\mathrm{a}}(0.39)$ \\
R50 & $7.84^{\mathrm{b}}(1.39)$ & $0.89^{\mathrm{a}}(0.01)$ & $0.72^{\mathrm{a}}(0.01)$ & $5.01^{\mathrm{b}}(0.79)$ \\
R70 & $9.39^{\mathrm{c}}(1.81)$ & $0.89^{\mathrm{a}}(0.01)$ & $0.73^{\mathrm{a}}(0.02)$ & $6.07^{\mathrm{c}}(0.99)$ \\
\hline
\end{tabular}

528 Values in parentheses are the standard deviations. Means in the same column without a common

529 letter are significantly different $(p<0.05)$ according to the LSD multiple range test $(n=12)$; R0:

530 control sponge cake, R30: sponge cake with $30 \mathrm{~g} / 100 \mathrm{~g}$ of fat replacement; R50: sponge cake

531 with $50 \mathrm{~g} / 100 \mathrm{~g}$ of fat replacement; R70: sponge cake with $70 \mathrm{~g} / 100 \mathrm{~g}$ of fat replacement.

532 
533 Table 5. Proportion of starch ( $\mathrm{g}$ starch/100 g sponge cake) digested during in vitro

534 digestion of sponge cakes.

\begin{tabular}{ccccc}
\hline & \multicolumn{4}{c}{$\mathbf{g}$ starch/100g sponge cake } \\
\cline { 2 - 5 } Formulation & $\mathbf{2 0}$ in & $\mathbf{6 0} \mathbf{~}$ in & $\mathbf{9 0}$ min & 120 min \\
\hline R0 & $46.06^{\mathrm{a}}(0.36)$ & $54.16^{\mathrm{a}}(0.00)$ & $56.46^{\mathrm{a}}(1.09)$ & $58.51^{\mathrm{a}}(1.33)$ \\
R30 & $47.94^{\mathrm{a}}(1.45)$ & $57.32^{\mathrm{ab}}(0.00)$ & $58.17^{\mathrm{a}}(0.72)$ & $58.94^{\mathrm{a}}(2.53)$ \\
R50 & $48.79^{\mathrm{a}}(1.45)$ & $58.43^{\mathrm{b}}(2.05)$ & $61.50^{\mathrm{b}}(0.84)$ & $61.92^{\mathrm{a}}(0.48)$ \\
R70 & $40.51^{\mathrm{b}}(1.81)$ & $52.11^{\mathrm{c}}(1.33)$ & $54.16^{\mathrm{c}}(1.09)$ & $52.20^{\mathrm{b}}(1.21)$ \\
\hline
\end{tabular}

535 Values in parentheses are the standard deviations. Means in the same column without a common

536 letter are significantly different $(p<0.05)$ according to the LSD multiple range test $(n=2) ; R 0$ :

537 control sponge cake, R30: sponge cake with $30 \mathrm{~g} / 100 \mathrm{~g}$ of fat replacement; R50: sponge cake

538 with $50 \mathrm{~g} / 100 \mathrm{~g}$ of fat replacement; R70: sponge cake with $70 \mathrm{~g} / 100 \mathrm{~g}$ of fat replacement. 


\section{FIGURE CAPTIONS}

541 Figure 1. Confocal laser scanning microscopy (CLSM) images of sponge cake batters 542 R0, R30, R50 and R70. R0: control sponge cake, R30: sponge cake with $30 \mathrm{~g} / 100 \mathrm{~g}$ of 543 fat replacement; R50: sponge cake with $50 \mathrm{~g} / 100 \mathrm{~g}$ of fat replacement; R70: sponge 544 cake with $70 \mathrm{~g} / 100 \mathrm{~g}$ of fat replacement. sg: starch granules, fg: fat globules.

545 Magnification 40X.

547 Figure 2. Scanned images of whole R0, R30, R50 and R70 sponge cakes, $5 \times 5 \mathrm{~cm}$ 548 field, and respective binarized images. R0: control sponge cake, R30: sponge cake 549 with $30 \mathrm{~g} / 100 \mathrm{~g}$ of fat replacement; R50: sponge cake with $50 \mathrm{~g} / 100 \mathrm{~g}$ of fat replacement; R70: sponge cake with $70 \mathrm{~g} / 100 \mathrm{~g}$ of fat replacement. Arrows: diffusion 551 pathways

Figure 3. Mean consumer acceptability values of the different sponge cakes. Means in the same attribute without a common letter are significantly different $(p<0.05)$ according to the LSD multiple range test $(n=140)$; R0: control sponge cake, R30: sponge cake with $30 \mathrm{~g} / 100 \mathrm{~g}$ of fat replacement; R50: sponge cake with $50 \mathrm{~g} / 100 \mathrm{~g}$ of fat replacement; R70: sponge cake with $70 \mathrm{~g} / 100 \mathrm{~g}$ of fat replacement.

Figure 4. Field emission scanning electron microscopy (FESEM) images of R0, R30,

560 R50 and R70 sponge cakes. R0: control sponge cake, R30: sponge cake with 30 $\mathrm{g} / 100 \mathrm{~g}$ of fat replacement; R50: sponge cake with $50 \mathrm{~g} / 100 \mathrm{~g}$ of fat replacement; R70:

562 sponge cake with $70 \mathrm{~g} / 100 \mathrm{~g}$ of fat replacement. sg: starch granules, o: oil.

563 Magnification 200x. Bar $=20 \mu \mathrm{m}$.

564 

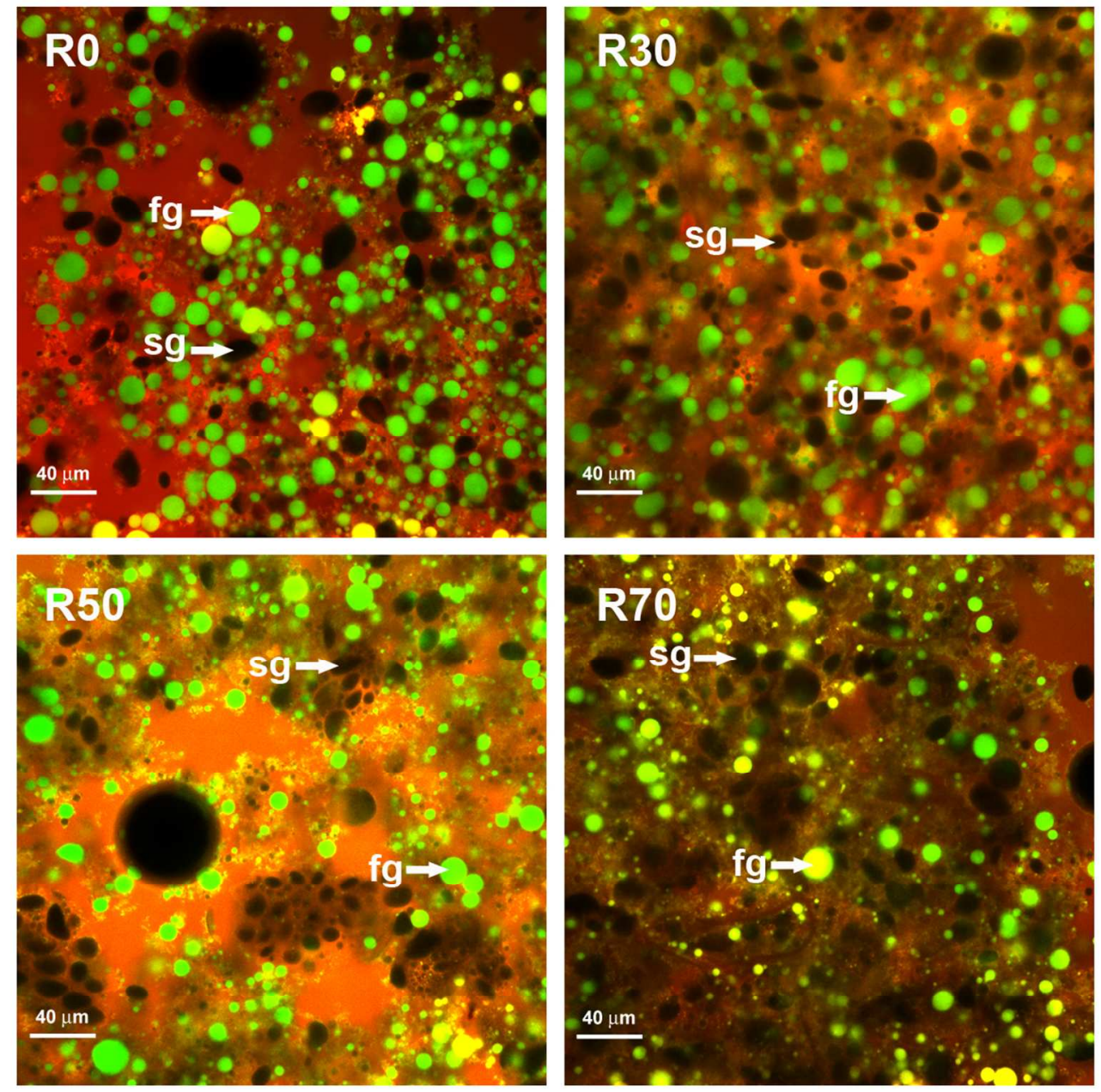

$105 \times 105 \mathrm{~mm}(300 \times 300 \mathrm{DPI})$ 

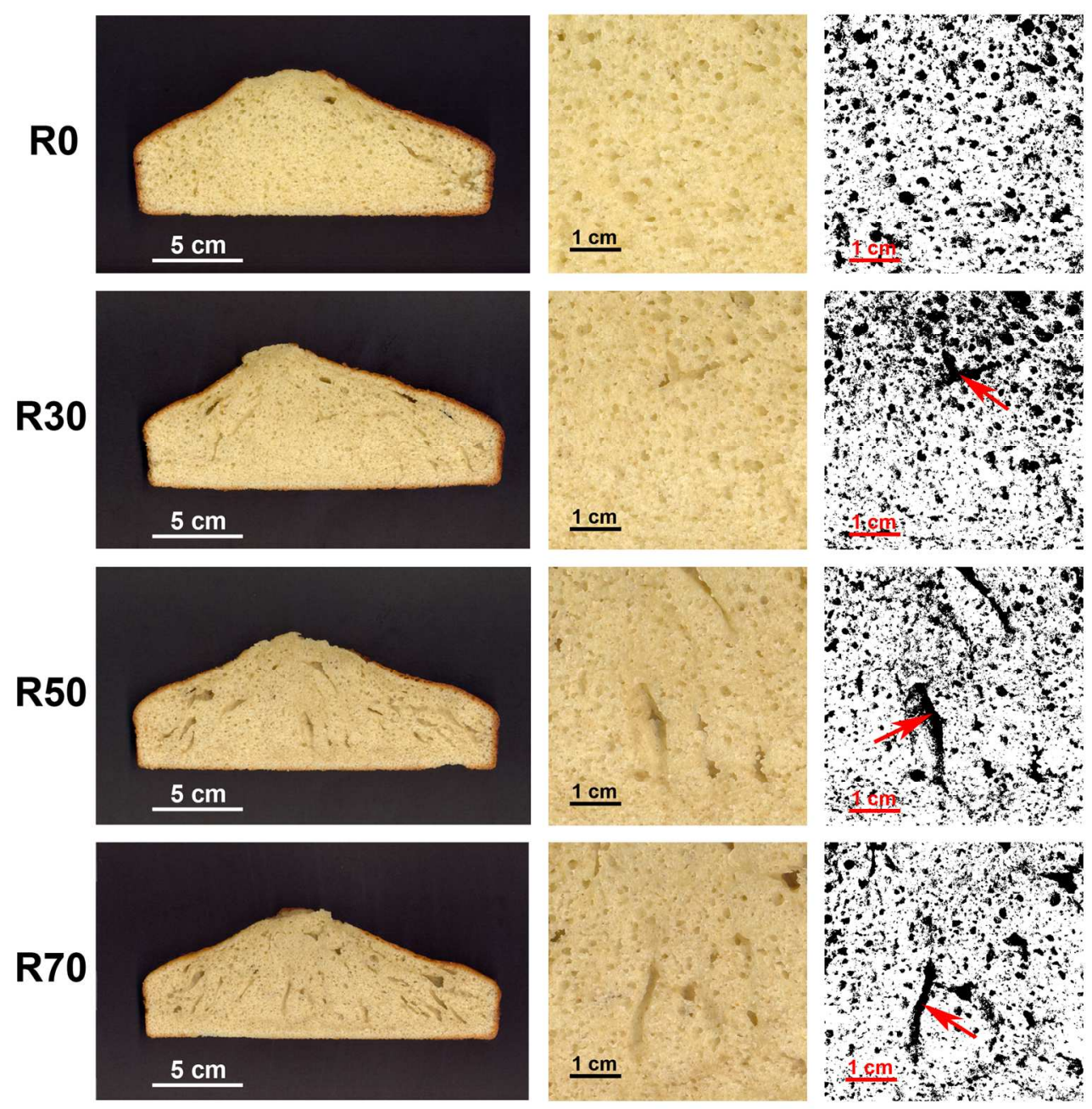

$165 \times 167 \mathrm{~mm}(300 \times 300$ DPI $)$ 


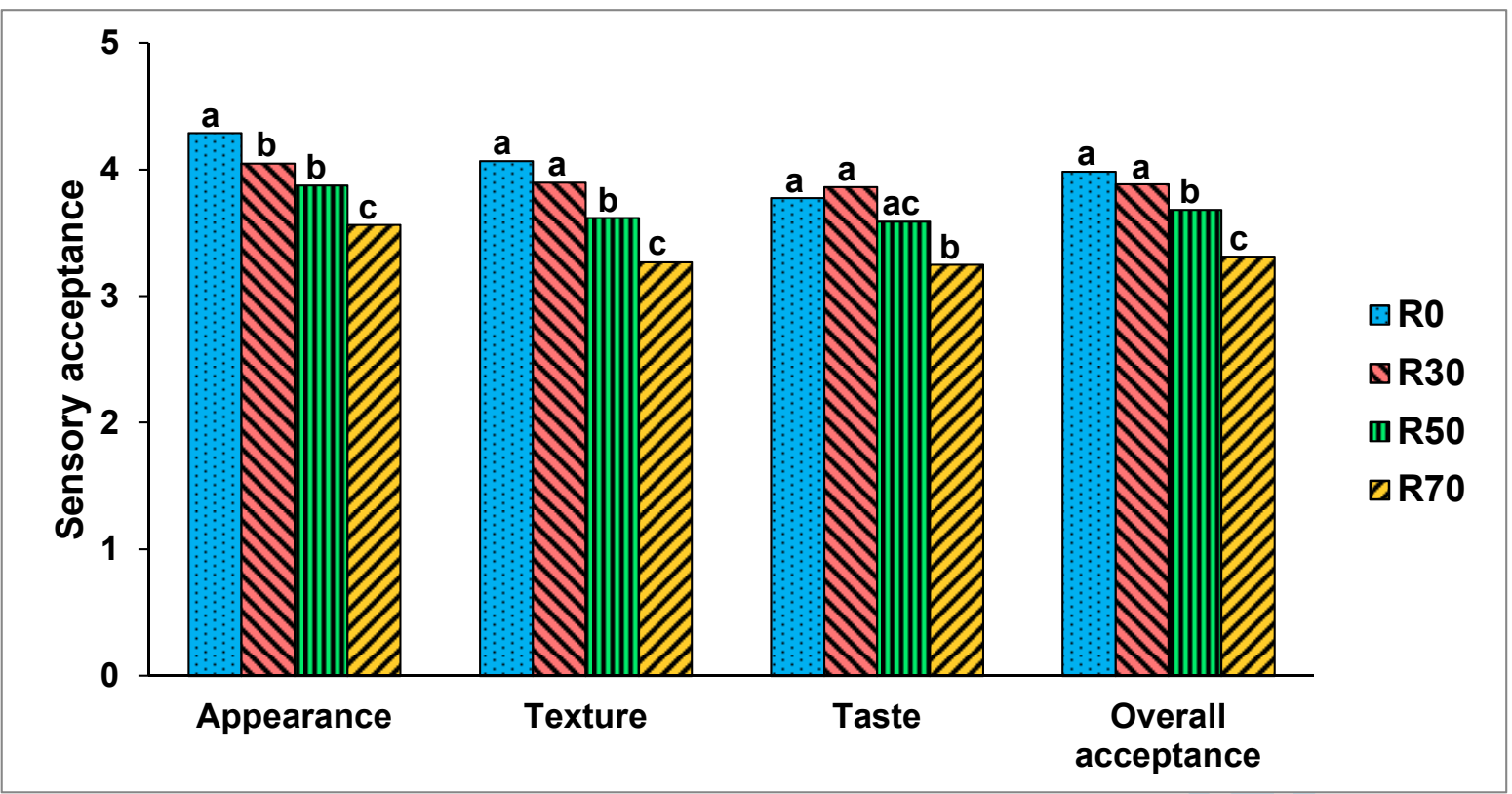



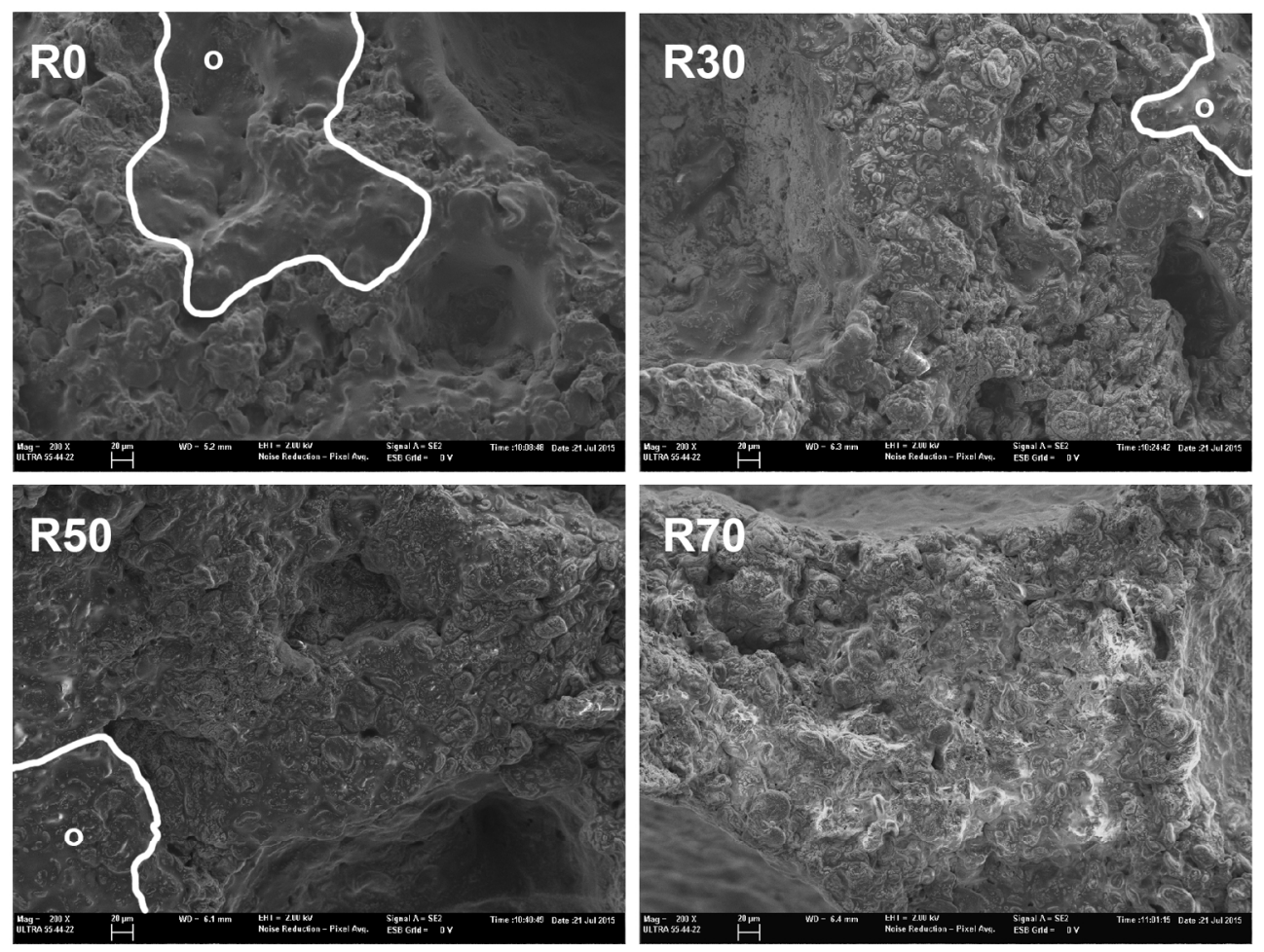

$155 \times 117 \mathrm{~mm}(300 \times 300 \mathrm{DPI})$ 
Answer to editor and reviewer

Comments to the Author:

Please address the comments of the reviewer and mine below in a separate cover letter and make all corrections in red font in the revised manuscript.

- Line 154 to 160 Why do you need to include IW in the equation? Why not just use the difference in weight before and after baking?

We decided to include IW in the equation because the initial content of water is very different as we need to add water depending of the amounts of Optisol used in the formulation. We have done it in this way in previous works as that published in Journal of Food Science:

Rodriguez-Garcia J, Puig A, Salvador A, Hernando I. 4852012. Optimization of a sponge cake formulation with inulin as fat replacer: structure, physicochemical, and sensory properties. J Food Sci 77(2): C189-C97.

- Line 237 Why was amylase not included in the procedure?

The pancreatin used in this study includes amylase. The P3292 pancreatin (Sigma-Aldrich)

contains:trypsin, amylase, Lipase, ribonuclease and protease produced by exocrine cells of the porcine pancreas.

The composition of the pancreatin has been added to the manuscript (Lines 240-241)

- Line 275 to 276 R50 seems to have less darkness than the other samples and the control. Please clarify statement.

It was a mistake. This sentence has been changed into "At the highest substitution level (R70) (Line 278)"

- Line 325 The values decreased not rose for a* as more fiber was added. Please revise statements in this section as the reference found the opposite to what you found.

In the crumb, $a^{*}$ values increased from $-2,23$ in $R \theta$ to $-0,20$ in R70, as observed by Lee et al. (2004). In fact they also found negative values for $a^{*}$ when using low levels of substitution $(e, g$. $20 \%$ of flaxseed powder instead of shortening) 
- line 359 to 364 The error bars on figure 3 overlap which means the samples and control are not different at all. Please carefully review the results and revise your statements.

It is true that the error bars in the figure overlap, which can lead to misunderstandings. In fact, in acceptability studies conducted with consumers the results are usually presented without error bars because acceptability can vary a lot among consumers. So, the statistics are often given only with the letters indicating the significant differences (or their absence). Some papers where the acceptability results are presented in this way are:

- Rodríguez-García J. et al. 2012. Optimization of a sponge cake formulation with inulin as fat replacer: structure, physicochemical, and sensory properties. J Food Sci 77(2): C189-C97.

- Corral, S. et al. 2014 Effect of fat and salt reduction on the sensory quality of slow fermented sausages inoculated with Debaryomices Hansenii yeast. Food Control 45: 1-7

- Tarancón, A. et al. 2015. Use of healthier fats in biscuits (olive and sunflower oil): changing sensory features and their relation with consumers' liking. Food Research International 69 (2015) 91-96.

- Laura Laguna et al.2012. Balancing texture and other sensory features in reduced fat short-dough biscuits. Journal of Texture Studies 43: 235-245.

- Figure 4 I cannot see the starch granules that are identified with arrows. Please clarify the figures or remove the identification of starch granules.

We agree to the editor. The starch granules are hard to distinguish. We have removed their identification in the figure (Line 562).

- lines 395 to 399 Please explain why digestibility changed.

The explanation has been added to the manuscript (Lines 402-408). "Adding fibre when processing foods is known to Limit starch gelatinisation and mask the starch granules, increasing the proportion of resistant starch as observed by Hardacre et al., (2015). This could be also related to the field emission scanning electron microscope (FESEM) images, where the starch granules in 
the $R 70$ cake matrix were observed to be very compact within the matrix, which would limit their physical accessibility to the digestive enzymes."

Reviewers' Comments to the Author:

Reviewer: 1

Comments to the Author

- L98-108 L113, Table 1: A typical sponge cake is made based on the flour, sugar, and eggs. However, a oil was used in your cake preparation. Citation(s) should be mentioned with brief explanation for the oil usage in a sponge cake preparation.

The use of oil instead of shortening in products as sponge cakes and muffins is typical in Mediterranean countries. Some references where oil is used in these products have been added in the manuscript (Lines 108-110). "Oil was used instead of shortening as usually done in Mediterranean countries (Rodriguez-Garcia and others, 2012; Martinez-Cervera and others 2011)." The explanation about how to use oil in sponge cakes preparation is provided in Line 124-125 (the oil was finally placed on the top)

- L126: batter quantities for being placed in a pan should be mentioned. Total amounts of the prepared batters were different, due to the different amounts of the fat replacers. It may affect the optimum cake texture.

Yes, it is true. It may affect texture and other characteristics as height. We always use the same amount of batter (700 g) for each cake. It has been added to the manuscript (Line 128) as we forgot to mention it in the previous version.

- L282-295: Data of weight loss and cake height should be presented.

Data have been included in Table 2

-L391-399 L408-410 Table 4.: The digestibility significantly increased or the same with the increased substitution levels of R30 or R50, but significantly decreased with the highest substitution levels of R70, in all the digestion periods. More explanation is needed for the sudden decrease with the samples with R70 citing more references.

An explanation had been included following the reviewer's suggestion (Lines 402-408) 
- L401-413: More discussions seem to be needed. Most of the results are jumping to the conclusions such as "clean-labeled ...". To me, sunflower oil is more natural than the processed OptiSolTM5300

This section has been rewritten trying not to list again the results and avoiding the jump to the last conclusion. The idea of preparing a low fat/low calorie product has been reinforced in this new version as sunflower oil is natural but more caloric than its replacer- Optisol+water (Lines 411-419). 